Journal of Engineering and Applied Sciences 14 (20): 7448-7452, 2019

ISSN: 1816-949X

(C) Medwell Journals, 2019

\title{
Electroencephalography (EEG) for Control the Luminaire System with Arduino UNO
}

\author{
Intisar Mohsin Saadoon and Qabas Abdal Zarhaa Jabbar \\ Department of Computer Science, College of Education, Mustansiriyah University, Baghdad, Iraq \\ dr.intisar_muhson@uomustansiriyah.edu.iq
}

\begin{abstract}
Electroencephalography (EEG) is a technique of reading the nerve electrical activity of the human brain by placing the EEG sensors into the scalp for the direct connection between the human brain and the computer. The main objective of this project was to read brain waves and generate control signals that used to control the luminaire system.
\end{abstract}

Key words: Electroencephalography (EEG), Graphical User Interfaces (GUT), brain wave, electrodes, Arduino, luminaire system

\section{INTRODUCTION}

The EEG signal obtained from the anterior lobe, when converted from the time domain to the frequency domain using the fast Fourier transform, reproduces different frequencies associated with different mental and emotional states (Fig. 1).

The main objective of this project was to read brain waves and generate control signals that used to control the luminaire system to build an initial model to assist real-time communication to alleviate the lives of the disabled (Myung and Yoo, 2013).

Graphical User Interfaces (GUI) are developed in two parts in this project. The first is part read the real-time brain signals the second part control the luminaire system with the help of Arduino UNO.

\section{MATERIALS AND METHODS}

Electroencephalography (EEG): One can get these days some of EEG systems at low cost prices from the market. Electrodes which installed on EEG systems can be connected to the computer wirelessly using Bluetooth bandwidth is $2.4 \mathrm{GHz}$.

The Arduino is open-source board have ARM processor can be configured by using software in development environment and used to gather and analyse the data to use it in real-time or stored for future analysis Fig. 2.

Electroencephalography (EEG) is the measurement of the electrical activity generated by neurons in the brain. A group of electrical signals generated by nerve cells in the brain are read by placing electrodes and analyzing that information that relates to the current emotional and emotional state of the brain (Fig. 3).

\author{
Hardware required \\ - Arduino UNO \\ - NeuroSky headset (Slave) \\ - $\mathrm{HC}-05$ Bluetooth module (Master) \\ - USB cable for Arduino \\ - Breadboard \\ - Jumper wires \\ - LEDs
}

The TX pin from the Arduino to the RXD pin on the $\mathrm{HC}-05$ removed becouse we are only interested in the data transmitted from the $\mathrm{HC}-05$ module to the Arduino Fig. 4.

EEG signal analysis: EEG signals vary by frequency band capacity (Lakshmi et al., 2014). Delta waves are high-frequency waves within the range $0-4 \mathrm{~Hz}$ occur during the deep sleep. Theta waves within the frequency range $4-8 \mathrm{~Hz}$ occur while meditating, inactivity or drowsiness. Alpha waves within the range $8-14 \mathrm{~Hz}$ and occurs during relaxation or meditation or close the eyes. $\mathrm{Mu}$ waves occur within the frequency band $8-13 \mathrm{~Hz}$ while the motor neurons are at rest. Mu suppression occurs when the user imagines moving or actually moving parts of his body. Beta waves within the frequency band $13-30 \mathrm{~Hz}$ and occur during the focus, alarm or activity status. Gamma waves within the frequency band $30-100 \mathrm{~Hz}$ during sensory processing of sound and sight (Fig. 5).

Brain-Computer Interface (BCI): Brain-Computer Interface $(\mathrm{BCI})$ is a system that measures brain activity and transforms this activity into artificial outputs (Sathurappan and Potty, 2013), thus, changing the interaction of outputs between the computer system and

Corresponding Author: Intisar Mohsin Saadoon, Department of Computer Science, College of Education, Mustansiriyah University, Baghdad, Iraq dr.intisar_muhson@uomustansiriyah.edu.iq 

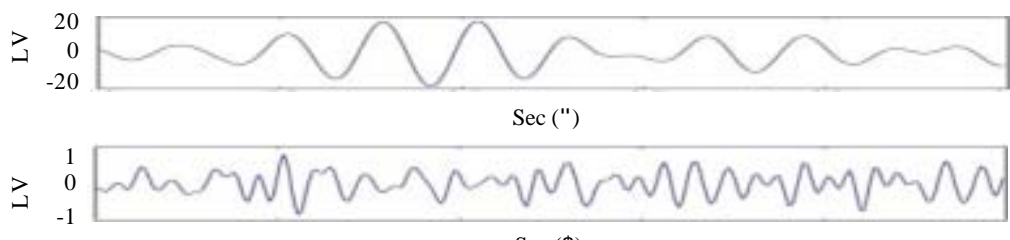

$\operatorname{Sec}(\$)$

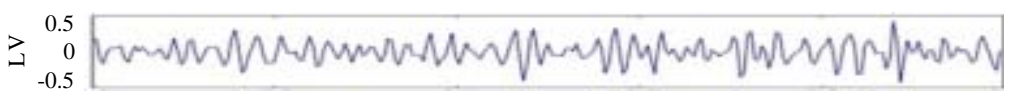

$\operatorname{Sec}(()$

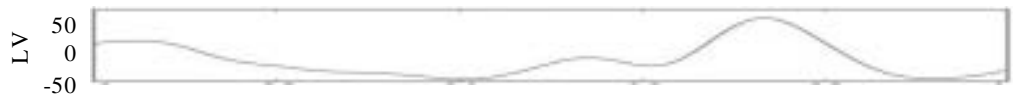

$\operatorname{Sec}())$

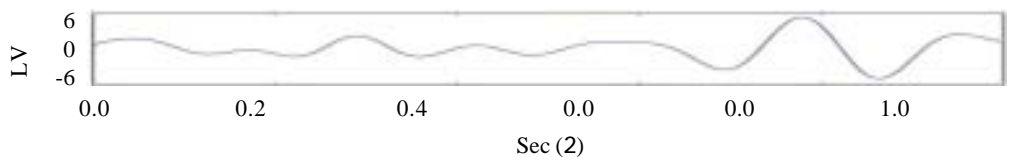

Fig. 1: Brain waves

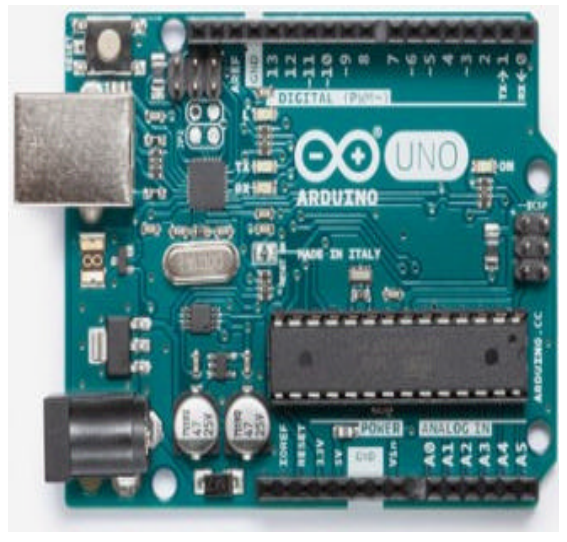

Fig. 2: Arduino UNO

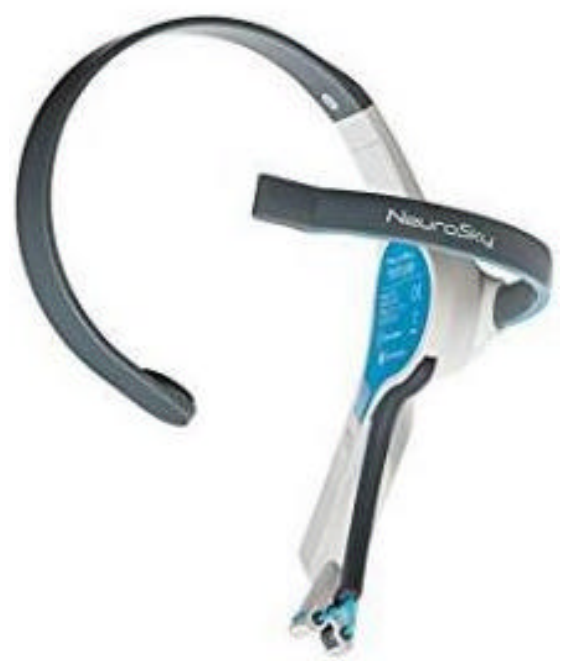

Fig. 3: NeuroSky headset

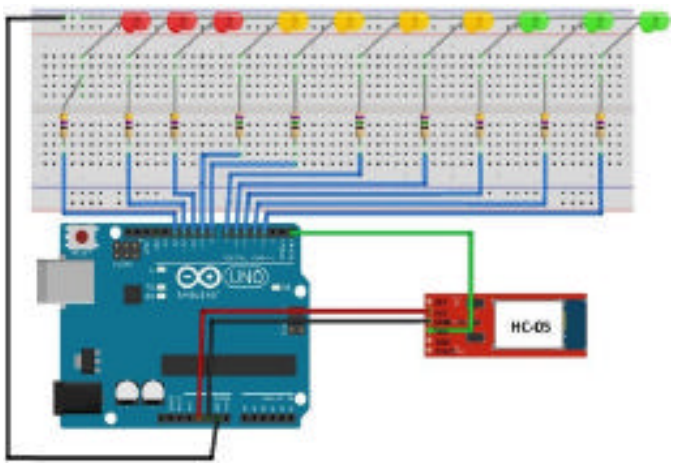

Fig. 4: HC-05 Bluetooth with Arduino

its external or internal environment (Wang, 2012) as show in Fig. 6. The computer interface system must contain four components:

- Activity must be recorded directly from the human brain using a specific sensor

- User feedback must be provided

- It should work in real time

- It must rely on intentional control

EEG signals taken by sensors within the frequency band from $1-100 \mathrm{~Hz}$, including noise signals (Almejrad, 2010). The active range pass filter for bandwidth from $0.1-100 \mathrm{~Hz}$ is designed to eliminate other frequency signals. The signal also contains $50-60 \mathrm{~Hz}$ noise resulting from the interference of the power line which can be reduced by protecting the wires. The signal picked up by the sensor is amplified for the first time by the amplifier (Azim et al., 2012). Active band pass filter 

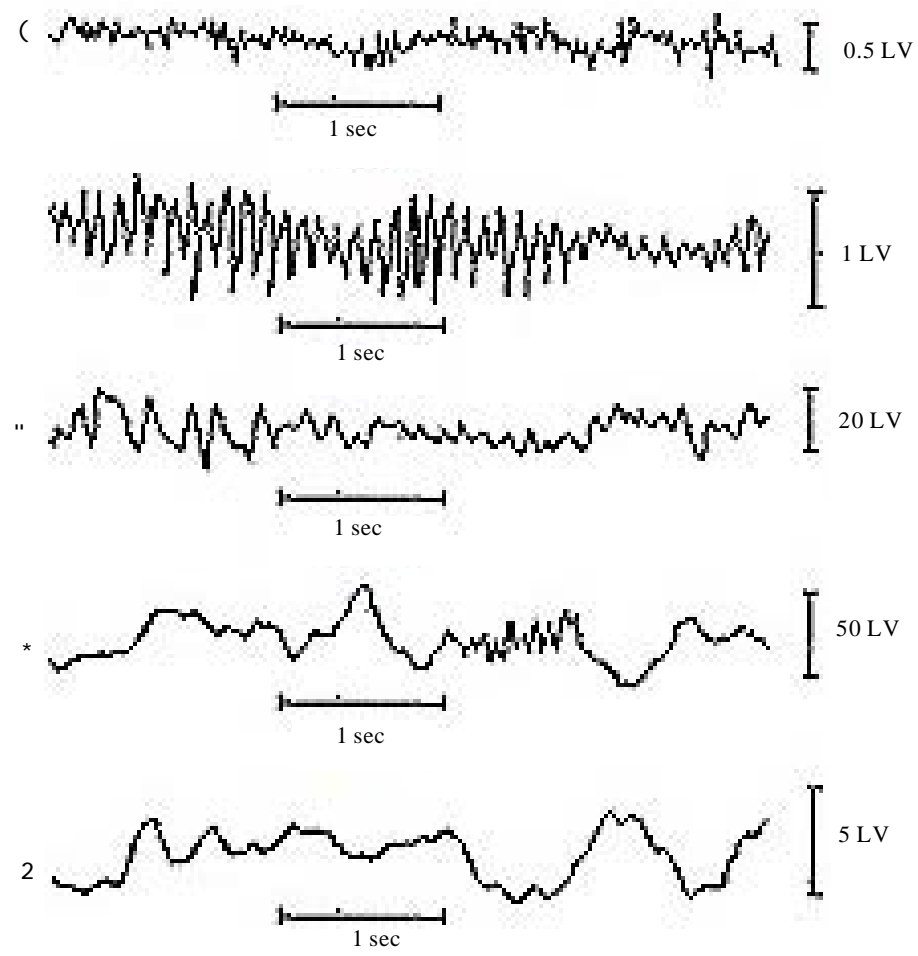

Fig. 5: Brain waves frequency band

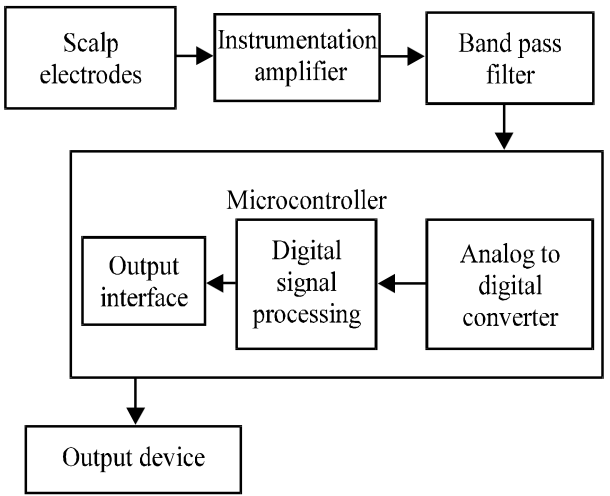

Fig. 6: Brain-computer interface

removes unwanted frequencies from the amplified signal. This analog signal is converted to a digital signal using an analog to digital converter in the ATmega 328P microcontroller. Digital signal is processed in the micro controller, thus, controls the LED input.

NeuroSky visualization: Reading the result of brain signals by NeuroSky visualization Fig. 7 after connect with specific port com to get results of attention, Meditation and Blink St:
- Attention: 694.044

- Meditation: 473.524

- Blink St: 573.648

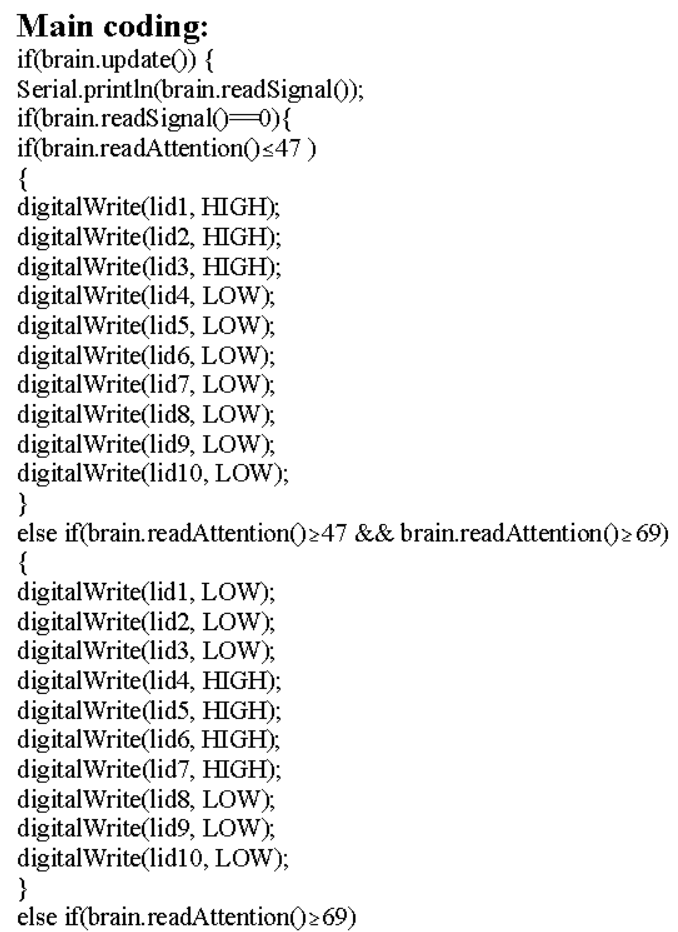




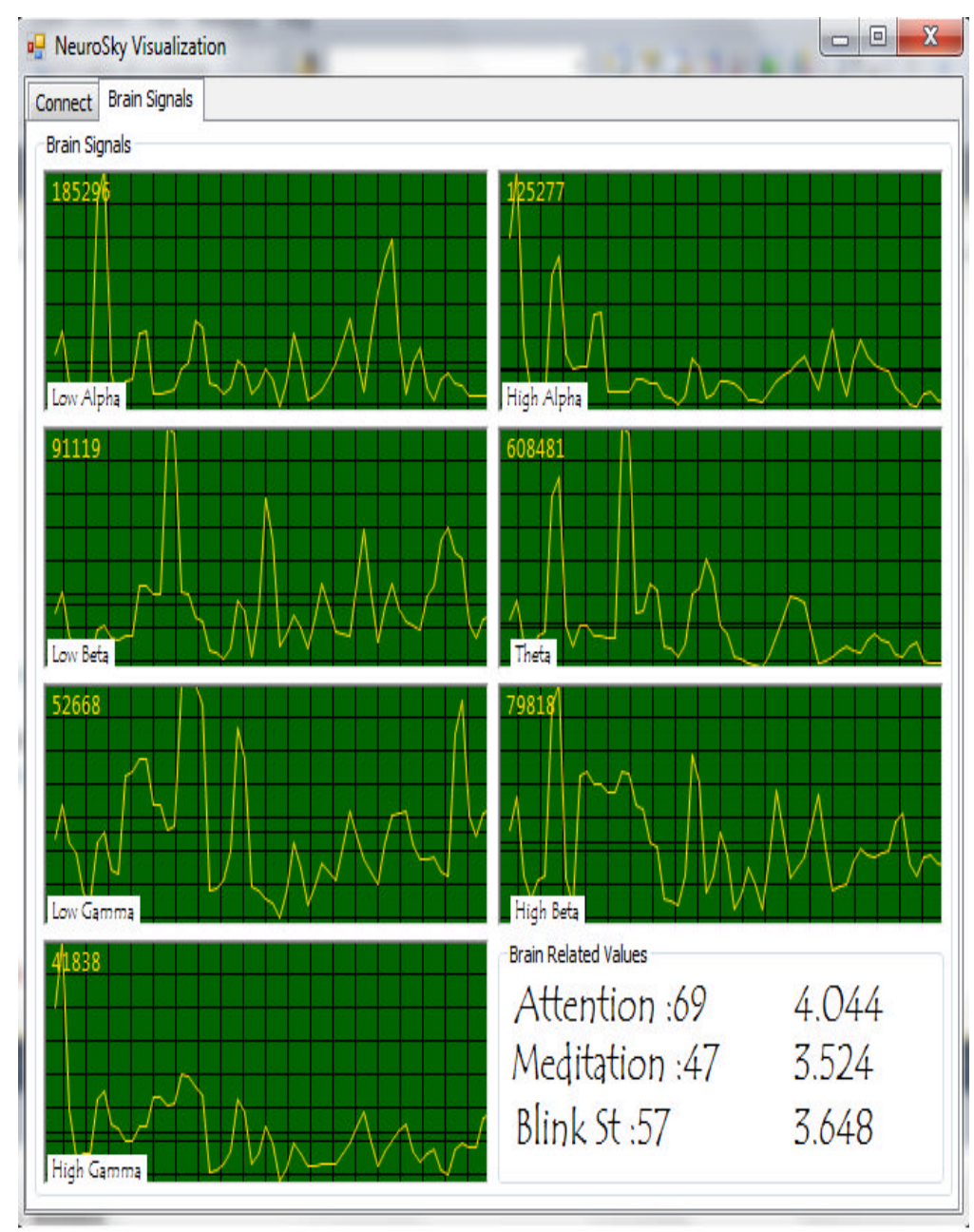

Fig. 7: NeuroSky visualization interface results

\{

digitalWrite(lid1, LOW);

digitalWrite(lid2, LOW);

digitalWrite(lid3, LOW);

digitalWrite(lid4, LOW);

digitalWrite(lid5, LOW);

digitalWrite(lid6, LOW);

digitalWrite(lid7, LOW);

digitalWrite(lid8, $\mathrm{HIGH}$ );

digitalWrite(lid9, HIGH);

digitalWrite(lid10, HIGH);

\}

else if (brain.readSignal $0>0 \& \&$ brain.readSignal $0<200)$

\{

digitalWrite(lid1, LOW);

digitalWrite(lid2, LOW);

digitalWrite(lid3, LOW);

digitalWrite(lid4, LOW);

digitalWrite(lid5, LOW);

digitalWrite(lid6, LOW);

digitalWrite(lid7, LOW);

digitalWrite(lid8, LOW);

digitalWrite(lid9, LOW);

digitalWrite(lid10, LOW);

\}

\section{CONCLUSION}

The main objective of this project was to read brain waves and generate control signals that used to control the luminaire system to build an initial model to assist real-time communication to alleviate the lives of the disabled. Graphical User Interfaces (GUI) are developed in two parts in this project. The first is part read the real-time brain signals the second part control the luminaire system with the help of Arduino UNO.

\section{ACKNOWLEDGEMENTS}

It is our pleasure to express our acknowledgment to the office editor team in the Computer Science Department as well as the Head of Computer Science Department in the College of Education and College of Science at Mustansiriyha University for their encouragement and support to accomplish such valuable applied researches. 


\section{REFERENCES}

Almejrad A.S., 2010. Human emotions detection using brain wave signals: A challenging. Eur. J. Sci. Res., 44: 640-659.

Azim, M.R., M.S. Amin, S.A. Haque, M.N. Ambia and M.A. Shoeb, 2012. Feature extraction of human sleep EEG signals using wavelet transform and Fourier transform. Proceedings of the 2010th International Conference on Signal Processing Systems (ICSPS), July 5-7, 2010, IEEE, Dalian, China, ISBN:978-1-4244-6892-8, pp: V3-701-V3-705.

Lakshmi, M.R., T.V. Prasad and V.C. Prakash, 2014. Survey on EEG signal processing methods. Intl. J. Adv. Res. Comput. Sci. Software Eng., 4: 84-91.
Myung, B.R. and S.K. Yoo, 2013. Development of 16-channels compact EEG system using real-time high-speed wireless transmission. Eng., 5: 93-97.

Sathurappan, N. and S.P. Potty, 2013. Measurement of environmental conditions and biomedical parameters using robotic-gripper. Proceedings of the 2013 International Conference on Advanced Computing and Communication Systems (ICACCS), December 19-21, 2013, IEEE, Coimbatore, India, ISBN: 978-1-4799-3506-2, pp: 1-6.

Wang, C.S., 2012. Design of a 32-channel EEG system for brain control interface applications. J. Biomed. Biotechnol., 2012: 1-10. 